\title{
Bringing the Benefits of David to Goliath: Special Economic Zones and Institutional Improvement
}

\author{
Christopher A. Hartwell ${ }^{a, b}$
}

\begin{abstract}
The theory behind special economic zones (SEZs) focuses on their role in overcoming broader policy failings in a country. This paper hypothesizes that the ability of smaller countries to reform more quickly provides a theoretical 'missing link' as to how SEZs can assist reform, developing the idea of SEZs as a 'small country in a large country.' Using a new database, the paper tests this proposition, examining if SEZs have actually been able to spur on institutional improvement in large countries. Results show that SEZs do influence the institutional development of a country, contingent upon prevailing institutional trends.
\end{abstract}

JEL codes: P48, O43, H10

Keywords: special economic zones, institutional development, property rights, small countries

${ }^{a}$ Center for Social and Economic Research (CASE), al. Jana Pawła II 61, office 212, Warsaw 01-031, POLAND

${ }^{\mathrm{b}}$ Kozminski University, UI. Jagiellonska 57, Warsaw 03-301, POLAND

Correspondence: Christopher.Hartwell@case-research.eu 
ACKNOWLEDGEMENTS: The author wishes to thank the editors, two anonymous referees, Katarzyna Sidło, and participants at the CASE Conference on Special Economic Zones in April 2015.

\section{Introduction}

Special Economic Zones (SEZs) have proliferated immensely over the past 35 years, starting from Ireland's Shannon free trade zone in 1958 and Taiwan's Export Processing Zones in 1966 and continuing through China's successful experience in Shenzhen from 1979 on. Growing from a mere 176 zones in 47 countries in 1986, by 2006 the International Labour Organization (ILO) counted 3,500 zones in 130 countries (Boyenge 2007), a number that the World Bank puts closer to 4,300 SEZs in 2015. ${ }^{i}$

SEZs have been utilized for a number of purposes over the years: to attract FDI (Graham 2004); as a laboratory for policy experimentation (Heilmann 2008); to support broader policy reform efforts (Ge 1999); or as a 'pressure-release valve' to alleviate large-scale unemployment (FIAS 2008). Through each of these first-order effects, it is presumed that an SEZ will then create beneficial second-order economic outcomes, such as increased growth, higher exports, or lower unemployment rates.

But while there have been many works researching these second-order effects of SEZs (see, inter alia, Rosemary et al. 1988 or Wang 2013), there is less understanding of the first-order effects. In particular, the channels in which policy reform benefits would arise in an SEZ have for the most part been assumed away, with only Moberg (2015) attempting to put SEZs into a political economy framework. If SEZs are to allow for policy experimentation and support policy reform, how would this flow back to the rest of the country? This question is of interest from a political economy standpoint because, concurrently with the proliferation of SEZs, the world has seen an overall trend towards policy reforms over the past two decades geared towards improving institutions. While the global financial crisis may have slowed 
progress in these institutional reforms (Hartwell 2013), on the whole the world has become much more welcoming of property rights and with less red tape than in decades past.

Perhaps not coincidentally, the leaders in institutional reforms over the past three decades have almost uniformly been smaller countries. Of the top 20 countries in the World Bank's Doing Business Report for 2015, only one country has more than 100 million citizens (the United States), while 12 countries out of the top 20 have less inhabitants than Jakarta (Table 1). Similarly, $60 \%$ of the world's most competitive economies (as measured by the World Economic Forum) have smaller populations than the city that started the modern SEZ trend, Shenzhen in China. ${ }^{\text {ii }}$ The innate traits of smaller countries may have enabled this rush to reform more easily than larger and/or highly centralized countries. As Katzenstein (1985) noted, tinier sovereign constructs tend to have voluntary and informal cross-issue policy coordination that allow for broader-based reform. Moreover, as Schwartz (1994) postulated, small states are forced to adapt sooner than larger countries due to their more vulnerable nature. This sense of urgency means that reforms may be adopted more quickly than in Russia or Brazil, where the transaction costs of institutional reform outweigh short-term economic pain.

[Table 1 here]

Following on from these separate-yet-linked observations, this paper breaks new ground to examine the effects of SEZs on institutional reform from the point of view of a small country. Drawing on a newlycompiled database of SEZs around the world, and building on the literature on institutional economic geography (Boschma and Frenken 2006, Mackinnon et al. 2009), this papers tests three separate hypotheses. In the first instance, we develop the idea of SEZs as a 'small country in a large country,' creating a distinct entity within an existing institutional structure which mimics small and decentralized 
sovereign; such a theoretical construct is crucial to form the link between the supposed benefits of SEZs and how these benefits might be transmitted to the rest of the 'host' country. Secondly, and more empirically, this paper examines if the size of a country matters for its institutional structure, drawing on the 'small country' literature (see Rose 2006) but updating it by focusing exclusively on institutions. The results below provide evidence that smaller is better when it comes to key institutions.

Finally, and the main contribution of this paper, is examining the effect that SEZs may have on their home country's institutional evolution. Can an SEZ, comprised of 'locally distinctive institutional architectures' help to 'shape evolutionary trajectories' in their country (Gertler 2010:1)? The econometric results show that SEZs can indeed improve some specific institutions, namely ones that they are meant to improve on a small-scale, such as property rights and trade institutions. While the size of the influence can vary, on average, SEZs may be an effective tool for policy and institutional experimentation.

\section{Three Hypotheses on SEZs and Institutions}

It is only recently that the researchers have begun to examine the reality of SEZs as regional spaces where institutions distinct from its 'host country' may develop. Part of this reticence has been due to a misunderstanding of how SEZs institutions actually operate within a broader country institutional system. Our first hypothesis addresses this issue:

H1: $\quad$ SEZs are in effect small countries 
The literature has had some difficulty in identifying exactly the 'special' nature of SEZs, with the most prevalent classification of these zones as a 'foreign enclave' (Chaudhuri and Yabuuchi 2010, Ouma 2012), a definition that the father of the modern SEZ, Deng Xiaoping, himself utilized (Kamath 1990). Amin (1999) speaking of both enclaves and exclaves, expanded upon this idea to note that such zones are 'path dependent and artificially constructed economic realit[ies] that... create [their] own specific economic conditions, incentives and benefits' (Gareev 2013:114). These incentive structures and institutions are supposed to be wholly alien to the host country, as in the prominent cases of China and India, thus warranting the 'foreign' appellation.

However, the enmeshing of SEZs within a country political institutional framework makes the idea of 'foreignness' semantically and factually incorrect. ${ }^{\text {iii }}$ The more accurate conception of SEZs is that they are in fact small countries within larger countries, more a microcosm of a larger country but one that is distinct enough to be its own entity. This small country idea provides a more coherent framework for thinking about how SEZs work within a country than the idea of 'enclaves,' by focusing on their dual nature encompassing both 'foreign' and 'domestic' aspects.

Several attributes of SEZs allow them to be described as small countries rather than enclaves. As a smaller administrative unit with great autonomy, SEZs enjoy the benefits that smaller countries have, including less pressure from a large number of interest groups, population homogeneity in terms of culture and preferences, lower transaction costs to acquiring information, and faster pass-through from policies to results. These economies of (small-) scale mean greater flexibility and more responsiveness from policymakers to businesses and investors, as well as greater likelihood of consensus. 
Of course, all of these attributes could be due to 'market-preserving federalism' (Weingast et al. 1995), where political decentralization allows for institutional experimentation. But the idea of the special economic zone goes beyond creating merely another sub-national unit, or even endowing it with additional powers, and into creating an economic institutional form that is actually distinct and absent from the host country. It is this reality that separates SEZs from other sub-national units such as local or municipal governments, which are tightly enmeshed in both the political and economic institutions of the host country. And while development policies are pushed off to regional and local governments during processes of decentralization (Li and Wei 2010), institutional reforms such as SEZs remain distinct from these local procedures.

In fact, there is a wilful design to create a great divergence between economic institutions in the zone and host country, especially in countries that are attempting a transition from one system to another (as China and other Asian countries did). The key difference between SEZs and sub-national administrative units, however, is that, much like a Switzerland, a Lichtenstein, or an Andorra, the economic institutions which arise in an SEZ are only meant to govern a very small population and area. That is, they are built with 'small' in mind rather than aspiring to governing a unit of larger size or being a smaller part of a larger machine, creating institutions which are circumscribed to a specific area.

This reality of geography calls to mind the final and perhaps strongest argument for SEZs as small countries, as they are (at least) physically contained within a narrow geographical delineation. In the vast majority of SEZs, there are actually physical borders, subject to government control, much like an international border crossing - without such markers, the zone itself would be amorphous. But the stark delineation and often the procedures required to enter such a zone add another argument for conceptualising SEZs as their own small and distinct countries. 
To summarize, SEZs act as small countries because they have different enough economic institutions to be alien to the host country, even as their political institutions remain integrated, while also holding physical boundaries and different objectives to the territory around them. This reality takes us to the next hypothesis:

H2: $\quad$ Small countries have better economic (and political) institutions than larger ones

Of course, the theoretical construct of SEZs acting as a small country does not matter if this manifestation does not have a tangible relationship with institutional quality. Fortunately, there is a large literature examining the relationship between country size and institutional development, postulating that small may indeed be beautiful.

As a definitional point, there is little agreement on what a 'small' country is internationally. The World Bank defines 'small states' as having a population under 1.5 million people, but the Association for Small Island States includes Cuba, with over 10 million people (Crowards, 2002). This specific delineation of where small ends and big begins is somewhat beside the point, as the idea of 'smallness' is one of relativity rather than absolutes; how does a relatively smaller country, in a world which has tended towards agglomeration, create institutions, and are they qualitatively better on average than larger countries? In this sense, in the world of 2117, a 'small' country may encompass 100 million inhabitants but still be small relative to China or India with 10 billion people each.

Given this basic point, the extant literature has identified several channels through which size can matter for institutional development: 
- Administration and congestion costs (Alesina et al. 2005): As a country gets bigger, it becomes exponentially more difficult and costly to administer formal rules, meaning institutions become larger, unwieldy, and inefficient as a result. This problem is exacerbated if the country exhibits size along two dimensions, i.e. population and area, where reaching more remote parts of the country with formal institutions also becomes more difficult.

- Less heterogeneity/more homogeneity in the population (Alesina 2003): Perhaps more difficult to handle than a mere scaling up of administrative institutions is the difficulty that large countries have in scaling up citizen's preferences; that is, the delivery vehicles for public goods may exhibit economies of scale, but the preferences for those goods may not. Similarly, in regard to economic institutions, rules may be seen as increasingly less applicable to all voters in big countries, with laws and norms of conduct differing widely across a large land space. Part of this heterogeneity can be attributable to ethnolinguistic fractionalization, which tends to be more prevalent in big countries and correlates with low-quality institutions (LaPorta et al. 1999). Hiscox and Lake (2002) take up this theme to emphasize that countries that are more homogenous, as small countries tend to be, are more likely to adhere to the subsidiarity principle, which would ensure smaller and more tailored institutions as well. Thus, a country like Estonia may be more able to implement radical reforms that lead to effective property rights institutions where a sprawling pastiche such as Russia may not.

- Small countries tend to be more open (Rose 2006): Finally, smaller countries exhibit a crucial trait borne of necessity that has a direct impact on institutional quality. Their tendency towards openness, related to small market size and the lower cost of trade (as distances to ports or 
borders are smaller and transportation costs are less), often forces these countries to adopt better institutions. This can occur via two channels, either as countries adopt the institutional structures of international institutions such as the WTO (Al-Marhubi 2005), or, as in more recent work from Bhattacharyya (2012), with trade working to strengthen commercial interests, which then agitate for better contract enforcement.

Some empirical evidence also exists already regarding institutional quality in small countries. Olsson and Hansen (2011:613) provide the most recent and thorough treatment, noting that institutional quality often has the character of a local public good that is imperfectly spread across space from the core of the country to the hinterland.' Working from the assumption that a large territory is accompanied by valuable rents and a lack of openness (both of which tend to distort property rights institutions), their empirical exercise shows that size is negatively related to rule of law.

With SEZs acting as small countries, and small countries seemingly having better institutions, this logically leads to our third hypothesis:

\section{H3: $\quad$ SEZs may create better institutions in their home countries}

This last hypothesis should follow logically from our previous ones: given that SEZs are not foreign enclaves but instead act as small countries, can the SEZ use the advantages of small countries in creating institutions to diffuse institutional improvement back to the host? In other words, even though SEZs are contained physically, are the ideas they spawn able to be transmitted across internal borders? The idea of 'scalability' of institutions from the SEZ to the host country is not a new one, as it is embedded in the 
theoretical benefits of an SEZ (in particular in the idea of SEZs as a policy laboratory, see Xu and Chung 2014). But the idea of institutional improvement as something capable of being transmitted is somewhat novel, in that it presupposes that SEZs may act as a 'bridge to structural transformation' in Schrank's (2001) memorable phrase.

This idea of institutional transmission is predicated on two separate conditions: one, that new institutions actually grow in the SEZ, and two, that they may be transmitted. A vast literature exists on SEZs, regional/spatial economic development, and broader ideas of growth/competitiveness, but very little research can be found on the institutional effects of such policy experiments. For example, Hazakis (2014) takes an institutionalist approach to understand the success or failure of SEZs. While his paper contains much of relevance on spontaneous versus planned order within an SEZ, the analysis remains within the confines of SEZ borders and avoids interactions between the micro-institutions of the zone and the outside world. Similarly, and perhaps closest to this current paper, is Moberg (2015), who teases out from a political economy standpoint the institutional issues that could cause an SEZ to fail; while she mentions the scalability of SEZs and how successful SEZs are able to change national policy by becoming less 'special' (more generalised), left unexamined is the influence that SEZs can have on the institutional structure in which they are raised.

The dearth of research on the broader institutional influence of SEZs is an auspicious omission when one considers that perhaps the entire raison d'être behind SEZs is the understanding that 'special' zones are necessary to overcome the institutional failures that already exist within a country. In fact, broad-based institutional failings appear to be the norm in the vast majority of countries that have created SEZs, with SEZs explicitly located in a philosophical space outside of the normal regulations and legislation. One need only look at the lengthy list of SEZ pioneers in the 1970s and 1980s such as China, India, or even 
Mauritius to see this effect in action; in the case of China and India, the SEZ represented a capitalist island in a socialist sea, with institutional arrangements that were expressly forbidden in the rest of the country. Similarly, in Mauritius, the country's export processing zone (EPZ) was fashioned shortly after independence to create economic institutions fashioned to the country's strengths (Vandemoortele and Bird 2011). As noted in the spatial economics literature, which focus on clusters as 'growth poles' within a country (Turok 1993), SEZs appear to be fashioned as their own growth pole for institutions.

Of course, there is no guarantee that an SEZ would ensure better economic institutions, and the SEZ might actually facilitate institutional decline in some areas that could negate the benefits in investor protection or business environment. For example, evidence abounds at the country- and SEZ-level about the opportunities for corruption that an SEZ could create, as in Wallis' (2006) examination of SEZs being created expressly as vehicles for rent-seeking by politicians. Fenwick (1984) and Yeung et al. (2009) also point out the real difficulties in the Chinese example, where SEZs such as in Hainan were unable to escape their regular environment and became plagued with corruption (although Fenwick (1984) notes that the penalties for corruption in SEZs became incredibly high and helped to put an end to the practice). Similarly, Jenkins (2014) notes that there has been pervasive corruption in India's SEZs that leads, paradoxically, to land appropriation without compensation. It is difficult to fathom how an SEZ can build property rights and investor protection on land that has been acquired through coercion and corruption!

Arrayed against this evidence that SEZs might lead to some institutional deterioration, however, are broader philosophical points arguing for the idea of institutional improvement. While SEZs are not perfect solutions, in that they can privilege certain firms and geographical regions artificially at the expense of others, they may be second-best institutions; in an arena where the development of 'correct' 
economic institutions is stymied by political manoeuvring or repression, SEZs may offer the only possiblity for institutional improvement. Feenstra et al. (2013:289) has made this exact point in the context of China, noting that '[special economic zones] themselves are a type of institution that regulates processing trade and takes the place of having a strong court system.' In this manner, SEZs can act as a second-best option to remove distortions even though they are not optimal (Xu (2011) also stresses that SEZs engender regional competition, including in institutions). This theory of second-best can even be extended to the deleterious effects noted above, as even with an increase in corruption (a natural outgrowth of the political system that spawned the SEZ), the 'proper' institutions may continue to grow nonetheless, making the experiment on balance beneficial.

The trickier proposition relates to the transmission of institutions from SEZs to the host country, for this presupposes that SEZs do not remain 'special' for long; indeed, once the institutions have been generated within the small country of the SEZ, they are then reabsorbed into the larger country, rendering the SEZ somewhat superfluous. An argument in favour of this transmission comes from the reality that SEZs are less-than-foreign and retain strong cultural, linguistic, and institutional ties with the host country. This reality makes it much more plausible that SEZs can pass institutional development back to the country surrounding it, infecting the host with new institutional forms that are generated from the same cultural milieu. Indeed, there is substantial evidence that that institutional improvement may be transmitted from external sources via trade channels (Levchenko 2013), where the very act of trade amongst similarly-endowed countries spurs a race to the top in institutions. In a situation where transaction costs are far lower than those found in international trade, it is more likely that an SEZ could create institutional competition and, thus, improvement. 
This hypothesis may have its limits, however. In the first instance, it is plausible that transmission may not be possible for all institutions, simply because the institutional improvement that an SEZ is supposed to engender is also not uniform across all economic institutions. In particular, SEZs appear to offer security and incentives which cannot be found elsewhere in the country, in order to attract investment and propel growth; this restricts their focus to a small set of institutions, including contracting institutions (property rights), investor protection, and the business environment as related to trade or customs. With this narrow focus, development of political institutions is almost entirely absent (there is no 'enclave of democracy'), and other economic institutions such as financial institutions are also usually excluded from the benefits of an SEZ. Thus, institutional development from an SEZ is necessarily limited by the SEZ's own scope, creating difficulties in transmitting broader-based institutional improvement back to the host country.

Secondly, as Rodríguez-Pose and Gill (2005) correctly note, devolution of power may itself cause inefficiencies that are avoided at the central government level. This would also be applicable to transfer of power to SEZs, who may have the benefits of experimentation but without any of the hard budget constraints that are binding on the national government. Economic institutions that may be created in such an environment may not survive the reality of integration into national life. On the other hand, SEZs are less likely to have the institutional burdens that accompany devolution (i.e. the creation of new bureaucracies), specifically because their purpose is expressly to avoid such burdens. Wei and Li (2010), in the context of China, also note that regional decentralisation itself may create new institutional complexities simultaneously suited to the region but immersed in the culture of a country, meaning that transfer may be possible. 
This raises the final question, if the benefits of being a 'small country' can survive during the transmission from SEZ to host country. To continue our metaphor, does the host country fight the infection, with the same issues that stall broad-based reforms before the inception of an SEZ combining to deny the institutional improvements afterwards? Despite SEZs being essentially a political project directed from the very top of a highly centralized government, Gallagher (2002:348) notes that SEZs did contribute to 'spontaneous policy innovations of local officials, state-owned enterprise managers, and foreign investors.' On the other hand, the performance of SEZs in India have been hampered by the same political difficulties that existed at the federal level, with regulatory strictures and corruption preventing the SEZs from influencing institutional development (Aggarwal 2005). Somewhere inbetween are the experiences of the various SEZs in Africa, which may have been unable to transmit improvement to the rest of their countries due to distorted incentives (Farole and Moberg 2014) or due to the importation of foreign institutions into the SEZs rather than building upon existing indigenous institutions.

\section{Methodology and Data}

Empirically testing $\mathrm{H} 2$ and $\mathrm{H} 3$ is the goal of the rest of the paper.; as they examine different facets of the SEZ debate, they will require different econometric approaches. For Hypothesis 2 on the relationship between size and institutional quality, we structure a regression along the lines of Olsson and Hansen (2011):

(1) $y_{i}=\alpha$ Size $_{i}+\gamma$ Initial Level $_{i}+$ SInitial GDP $_{i}+\mu$ Macro $_{i}+\rho$ Legal Origin $_{i}+\varepsilon_{i}$ 
Where $y_{\mathrm{i}}$ is the average institutional score, Size is the (log) population of a country in millions, Initial Level is the earliest recorded score of the relevant institutional metric, and Initial GDP is same for GDP (the initial levels are not averaged over the period).

Additionally, a vector of macroeconomic controls which could plausibly influence institutions is included. Given the substantial number of macroeconomic variables that can be related to a country institutional score, and the relative lack of theoretical backing on which would be most important, I narrow down the large set of possibilities via Bayesian Model Averaging (BMA) in the mould of O'Hara and Sillanpää (2009) and De Luca and Magnus (2011). This somewhat atheoretical approach fits this exploration perfectly, given that the extant literature has only begun to examine the idea of macroeconomics influencing institutions, rather than the other way around. The BMA specification is that devised by De Luca and Magnus (2011) and Dardanoni et al. (2011) and implemented by Dardanoni et al. (2012) in Stata, where model space $I$ is defined as:

$$
\text { (2) } \bar{\beta}=\sum_{i=1}^{I} \lambda_{i} \widehat{\beta}_{l}
$$

In equation $2, \lambda_{i}$ represents non-negative random weights that sum to 1 , while $\beta_{i}$, is the model averaging estimate, based on assigned posterior probabilities. For this exercise, we have used a weighted-average least squares (WALS) prior, which allows for flexibility in the presence of heteroskedasticity and serial correlation, as well as non-spherical errors (Magnus et al. 2011). As Dardanoni et al. (2012:582) note, this 'choice of priors corresponds to a more intuitive concept of uncertainty about the role of the auxiliary regressors.' Upon completion of the BMA/WALS analysis, and using De Luca and Magnus' (2011) rule, I retain auxiliary variables which have an absolute value of $t$ - 
ratios over 1 (also satisfying the criteria that the variable's two standard-error confidence intervals do not include zero, as noted in Hartwell [2015]). ${ }^{\text {iv }}$

Finally, legal origin is derived from La Porta et al. (1999) to proxy for long-term institutional development effects. ${ }^{\vee}$ The institutional indicators utilized are three separate parts of the institutional environment that should logically be affected by country size, as noted in the theoretical discussion above: property rights, quality of government, and trade institutions (a complete explanation is given in Table 2 below).

[Table 2 here]

Due to the mostly time-invariant nature of country size and the reality that size may have effected institutional development, performing this exercise on time-series data will be of little use for this examination. Instead, it is more plausible to utilize a cross-sectional average of the measures shown above for all countries across the years available (as in Jayasuriya and Suri 2012), applying an OLS estimator with robust standard errors clustered on the country variable. As a further exploration of the relationship, estimates of a quantile regression as in Koenker and Basset (1978) are used to understand the effects of country size at the various levels of institutional performance.

\section{H3: $\quad$ SEZs may create better institutions in their home countries}

The heart of this empirical exercise is incorporating institutional change as a function of the presence of SEZs in a country. Given the 'moderate $N$, moderate $T$ ' nature of our data, we utilise an Augmented 
Mean Group estimator (AMG) as in Eberhardt and Teal (2011). The AMG estimator has several aspects which recommend it, including its assumption that both the technology parameters and factor loadings across countries are heterogeneous; however, it also captures time-invariant fixed-effects via the intercept across regression models (Eberhardt 2012). The AMG also accounts for spatial correlation and heteroskedasticity if present in the data, an issue that is plausible when applied to institutions, ${ }^{\mathrm{vi}}$ and can correct for endogeneity if the nature of the endogeneity is common to all panels.

However, what happens if the endogeneity is panel specific? In regard to SEZs, this is highly likely, as the decision to choose to establish an SEZ is predicated on many different variables. In particular, a country that already is high-income or with a high initial level of institutions may be less likely to start an SEZ, while a larger country may be more like to create SEZs, in order to combine the benefits of a small country with the scale-effects of being larger. Recognizing this reality, one can eschew the AMG approach for a regression that uses instrumental variables (IV), predicating the presence of an SEZ on country-specific factors such as GDP, institutional quality, and population size:

$$
\text { (3) } y_{i t}=\alpha S E Z_{i t}+\beta X_{i t}+\varepsilon_{i t}
$$

Where

(4) $S E Z_{i t}=\theta$ InitialGDP $P_{i}+$ Initial Institutions $_{i}+\epsilon_{i}$

Or

(5) $S E Z_{i t}=$ OInitialGDP $_{i}+\mu$ Population $_{i t}+\epsilon_{i}$ 
The choice of the particular instrumental variable will depend upon its econometric suitability as well as recourse to economic theory (in some specifications, as will be shown below, one or the other instrumentation approaches fits the model better).

In equations 3-5, two separate variables are utilized under SEZ: SEZ presence, which takes the variable of 1 for every year that a country had an SEZ, and number of SEZs, which is the actual number of zones in a country in a given year. Additionally, as in Equation $1, X_{i t}$ is a matrix of controls that can influence institutional development derived from the literature (Mijiyawa 2013), including growth, trade openness, financial openness (as captured by the Chinn-Ito (2008) indicator), GDP per capita, and inflation.

The preferred estimator for this instrumental variable analysis is an IV-GMM estimator, allowing for over-identification in the presence of heteroskedasticity in a manner more efficient than the usual 2SLS approach (which is itself a special case of the IV-GMM estimator). Crucial for our spatial analysis, Kelejian and Prucha (1998) have demonstrated that even in the presence of spatial error dependence, the IV method yields consistent and unbiased estimates when combined with robust standard errors.

\section{The Data}

To test these theoretical models, this paper makes use of a new (unbalanced) panel database of 110 countries with annual data from 1983-2012. The data for this exercise comes from a number of sources, including the World Bank, the International Country Risk Guide (ICRG), the IMF, and other publiclyavailable databases. A list of the institutional indicators is shown in Table 2, along with the largest possible coverage and the source of the data; as can be seen, the indicator for property rights has the 
longest time-series, while the World Bank data is relatively more recent. For our controls, most macroeconomic data comes from the World Bank World Development Indicators, with legal origin variables coming from La Porta et al. (1999). Geographic dummies were based on the geographic classification system used by the World Bank.

Finally, perhaps most importantly, the SEZ database used here is an entirely new construct, painstakingly compiled from the ILO (Boyenge 2007), public sources, government websites, previous research, and discussions with government officials. While not as comprehensive as other databases such as the ILO or the FIAS database from 2008, as noted above, the SEZ data encompasses both the presence of a zone and the cumulative number of zones in a given year, a new approach to tallying SEZs.

\section{Results and Discussion}

\section{Is Smaller Better?}

In regard to the question of small countries and their (possibly) superior institutions, Table 3 shows the results of the cross-sectional analysis relating country size to institutional quality for all institutional metrics. For each institution, the first column of Table 3 contains the complete model as shown in equation 1, while the second column retains only the relevant auxiliary variables after the application of Bayesian model averaging (with criteria as described above). As can be seen, on average, the size of a country's population appears to correlate with better institutions across the board, with the strongest correlations for investor protection (property rights) and control of corruption. Regulatory quality and importing delays is also negatively related to country size, albeit marginally (and only in the BMA regressions), while there is statistically no correlation between country size and how long it takes to export. The poor results in the trade institutions regressions may be due to the much shorter time span 
of data available (only from 2003, as opposed to 1983 as with investor protection), especially when one considers the technology available during this time frame that is able to overcome problems of size.

[Table 3 here]

As a further exploration of these correlations, the results of the quantile regressions allow us to see how population may affect countries at various levels of institutional quality. For example, in Table 4 Columns 1-3, we can see that lower levels of investor protection are more strongly affected by population size, with the effect decreasing slightly at the $75^{\text {th }}$ percentile (although still significant at the $1 \%$ level). Conversely the effects of population size on control of corruption expand with more corruption, perhaps because of the simple reality of more to corrupt. In regard to trade institutions, the effects are much more muted and variable, with population size only contributing (marginally) at the lowest percentile of delays for exports, and contributing at both the low and higher percentiles (but not the median) of delays for imports. Finally, regulatory quality, also with a smaller time span, exhibits consistent effects across percentiles of quality, although the negative effects of country size are only significant at the highest levels of quality.

[Table 4 here]

\section{Do SEZs improve institutions?}

This first step has mostly confirmed our hypothesis that small countries have better institutions, in particular property rights and control of corruption, as well as slightly better regulatory quality and slightly less import delays, on average. As we showed above, SEZs do operate as small countries within 
countries, leading us to our last hypothesis: can these small country benefits transmit to the host country?

[Table 5 here]

Using the specification noted in the last section, Table 5 shows the results of the IV-GMM regressions, including financial openness as well as trade openness. Correcting for the likely endogeneity of a country's choice to start an SEZ, with choice of instrumental variables based on econometric fit, it appears that SEZs do actually improve some of the basic institutions in its host country. In particular, property rights and regulatory quality are significantly improved by the presence of at least one SEZ, with additional SEZs having a positive, if more muted, impact as well. Trading institutions also fare well, as, on average, the presence of at least one SEZ leads to reductions of 12 days to export and 16 days to import. The results on trading institutions should be treated somewhat cautiously, however, as the chosen instrumental variables have weaknesses and apparently do not fit the model as well as with the other institutions examined.

A similar problem was encountered in instrumenting control of corruption, which showed substantial issues in using initial conditions and population as instrumental variables. However, this was circumvented by the use of the initial level of property rights as an instrumental variable, on the supposition that countries with pre-existing quality in investor protection would be able to also control their corruption. This approach did indeed work (shown in Column 10 of Table 5), but the results confirm Yeung et al. (2009) and show that the presence of an SEZ does lead to higher levels of corruption, even as it improves overall property rights. This result holds in the face of additional SEZs (Column 11), where each additional SEZ appears to reduce a country's control of corruption score by 
0.04 points. Thus, SEZs may indeed create spoils for political actors to fight for, with more spoils leading to more corruption.

\section{v. Conclusions}

This paper has explored the ability of special economic zones to influence the institutional development in their host country, in particular by asserting that SEZs tend to act as small countries within larger countries. Notwithstanding caveats noted above, the empirical and theoretical results presented here show that SEZs do in fact act as small countries, which is important, given that we demonstrate that small countries tend to have better institutions. The results of the IV-GMM exercise above also suggest that an SEZ's cultural integration with the host country allows them to generate even greater institutional benefits than would be suggested by the mere correlation between size and institutional improvement. Surprisingly, however, while SEZs may be a second-best solution to institutional improvement, they are still not optimal, as they create distortions which can engender rent-seeking behaviour. In this sense, SEZs may be a way to overcome short-term coordination problems in the same manner that a smaller country may, but the longer-term, seemingly intractable political issues that a larger country may face might overwhelm even a phalanx of SEZs.

This paper also opens the way for future research in for exploring other issues related to SEZs and the political economy of place-based policies: How do SEZs interact with the rest of their host country, as measured in the difference in SEZ institutional quality versus home-country quality? How do political institutions, and in particular political ties, affect corruption? What, if any, is the interaction between the number of SEZs and democratic accountability? These issues are beyond the scope of this paper, but are a fruitful area for researchers in this field. 


\section{REFERENCES}

Aggarwal, A. (2005). Performance of export processing zones: A comparative analysis of India, Sri Lanka and Bangladesh. Indian Council for Research on International Economic Relations Working Paper No. 155, http://icrier.org/pdf/wp155.pdf.

Al-Marhubi, F. (2005). Openness and Governance: Evidence Across Countries. Oxford Development Studies, 33(3-4), 453-471.

Alesina, A. (2003). The size of countries: Does it matter? Journal of the European Economic Association, 1(2-3), 301-316.

Alesina, A., Spolaore, E., and Wacziarg, R. (2005). Trade, growth and the size of countries. In Aghion and Durlauf (eds.), Handbook of economic growth, 1B. North Holland: Elsevier, 1499-1542.

Amin, A. (1999). An Institutionalist Perspective on Regional Economic Development. International Journal of Urban and Regional Research, 23(2), 365-378

Bhattacharyya, S. (2012). Trade liberalization and institutional development. Journal of Policy Modeling, 34(2), 253-269. 
Boschma, R. A., \& Frenken, K. (2006). Why is economic geography not an evolutionary science? Towards an evolutionary economic geography. Journal of Economic Geography, 6(3), 273-302.

Boyenge, J. P. S. (2007). ILO Database on Export Processing Zones, Revised. Geneva: ILO. http://www.ilo.org/public/libdoc/ilo/2007/107B09 80 engl.pdf.

Chaudhuri, S., and Yabuuchi, C. (2010). Formation of special economic zones, liberalized FDI policy and agricultural productivity. International Review of Economics \& Finance, 19(4), 779-788.

Chinn, M. D., and Ito, H. (2008). A new measure of financial openness. Journal of Comparative Policy Analysis, 10(3), 309-322.

Crowards, T. (2002). Defining the category of 'small' states. Journal of International Development, 14(2), 143-179.

Dardanoni, V., Modica, S., \& Peracchi, F. (2011). Regression with imputed covariates: A generalized missing-indicator approach. Journal of Econometrics, 162(2), 362-368.

Dardanoni, V., De Luca, G., Modica, S., \& Peracchi, F. (2012). A generalized missing-indicator approach to regression with imputed covariates. Stata Journal, 12(4), 575-604.

De Luca, G., and Magnus, J. R. (2011). Bayesian model averaging and weighted average least squares: Equivariance, stability, and numerical issues. Stata Journal, 11(4), 518-544. 
Driscoll, J. C., and Kraay, A. C. (1998). Consistent covariance matrix estimation with spatially dependent panel data. Review of Economics and Statistics, 80(4), 549-560.

Eberhardt, M. (2012). Estimating panel time-series models with heterogeneous slopes. Stata Journal, 12(1), 61-71.

Eberhardt, M., and Teal, F. (2011). Econometrics for Grumblers: A New Look at the Literature on CrossCountry Growth Empirics. Journal of Economic Surveys, 25(1), 109-155.

The Economist (2015). Special economic zones: Not so special. 4 April 2015.

Farole, T., and Moberg, L. (2014). It worked in China, so why not in Africa? UNU-WIDER Working Paper 2014/152, http://www.wider.unu.edu/publications/working-papers/2014/en GB/wp2014-152/.

FIAS (2008). Special Economic Zones: Performance, Lessons Learned, and Implications for Zone Development. World Bank, Washington, DC.

http://www.ifc.org/ifcext/fias.nsf/AttachmentsByTitle/SEZpaperdiscussion/\$FILE/SEZs+report April2008 .pdf.

Gallagher, M. E. (2002). 'Reform and Openness': Why China's Economic Reforms Have Delayed Democracy. World Politics, 54(3), 338-372.

Gareev, T. (2013). The special economic zone in the Kaliningrad region: development tool or institutional trap?. Baltic Journal of Economics, 13(2), 113-129. 
Ge, W. (1999). Special economic zones and the opening of the Chinese economy: Some lessons for economic liberalization. World Development, 27(7), 1267-1285.

Gertler, M. S. (2010). Rules of the game: the place of institutions in regional economic change. Regional Studies, 44(1), 1-15.

Graham, E. M. (2004). Do export processing zones attract FDI and its benefits. International Economics and Economic Policy, 1(1), 87-103.

Hartwell, C. A. (2013). Institutional Deterioration in Transition Economies: Playing Follow-the-Leader During the Global Financial Crisis? Transition Studies Review, 20(2), 131-147.

(2015). Après le déluge: Institutions, the Global Financial Crisis, and Bank Profitability in Transition. Open Review, on-line first, http://link.springer.com/article/10.1007/s11079-015-9349-9.

Hazakis, K. J. (2014). The rationale of special economic zones (SEZs): An Institutional approach. Regional Science Policy \& Practice, 6(1), 85-101.

Heilmann, S. (2008). Policy experimentation in China's economic rise. Studies in Comparative International Development, 43(1), 1-26. 
Hiscox, M.J., and Lake, D.A. (2002). Democracy, Federalism, and the Size of States. Available at SSRN: http://dx.doi.org/10.2139/ssrn.1002686.

Jayasuriya, D., and Suri, V. (2012). Impact of Smallness and Remoteness on Growth: the Special Case of the Pacific Island Countries. World Bank Pacific Futures Working Paper, https://cde.buseco.monash.edu/site/DefaultSite/filesystem/documents/ADEW/Jayasuria-SuriSmallness\%20and\%20Remoteness\%20Paper\%20Working\%20Paper\%20-\%2028032012.pdf.

Jenkins, R. (2014). India's SEZ policy: The political implications of 'permanent reform'. In Jenkins, Kennedy, and Mukhopadhyay (eds.), Power, policy and protest: The politics of India's special economic zones. Oxford: Oxford University Press, 39-71.

Kamath, S. J. (1990). Foreign direct investment in a centrally planned developing economy: the Chinese case. Economic Development and Cultural Change, 39(1), 107-130.

Katzenstein, P. J. (1985). Small states in world markets: Industrial policy in Europe. Ithaca: Cornell University Press.

Kelejian, H. H., and Prucha, I. R. (1998). A generalized spatial two-stage least squares procedure for estimating a spatial autoregressive model with autoregressive disturbances. The Journal of Real Estate Finance and Economics, 17(1), 99-121.

Koenker, R., and G. Bassett (1978). Regression Quantiles. Econometrica, 46(1), 33-50. 
La Porta, R., Lopez-de-Silanes, F., Shleifer, A., and Vishny, R. (1999). The quality of government. Journal of Law, Economics, and Organization, 15(1), 222-279.

Levchenko, A. A. (2013). International trade and institutional change. Journal of Law, Economics, and Organization, 29(5), 1145-1181.

Li, Y., \& Wei, Y. D. (2010). The spatial-temporal hierarchy of regional inequality of China. Applied Geography, 30(3), 303-316.

MacKinnon, D., Cumbers, A., Pike, A., Birch, K., \& McMaster, R. (2009). Evolution in economic geography: institutions, political economy, and adaptation. Economic Geography, 85(2), 129-150.

Magnus, J. R., Wan, A. T., \& Zhang, X. (2011). Weighted average least squares estimation with nonspherical disturbances and an application to the Hong Kong housing market. Computational Statistics \& Data Analysis, 55(3), 1331-1341.

Mijiyawa, A. G. (2013). Determinants of property rights institutions: survey of literature and new evidence. Economics of Governance, 14(1), 127-183.

Moberg, L. (2015). The political economy of special economic zones. Journal of Institutional Economics, 11(1), 167-190.

O'Hara, R. B., and Sillanpää, M. J. (2009). A review of Bayesian variable selection methods: what, how and which. Bayesian analysis, 4(1), 85-117. 
Olsson, O., and Hansson, G. (2011). Country size and the rule of law: Resuscitating Montesquieu. European Economic Review, 55(5), 613-629.

Ouma, S. (2012). The New Scramble for Africa. Regional Studies, 46(6), 836-838.

Park, B. G. (2005). Spatially selective liberalization and graduated sovereignty: Politics of neo-liberalism and 'special economic zones' in South Korea. Political Geography, 24(7), 850-873.

Rodríguez-Pose, A., \& Gill, N. (2005). On the 'economic dividend' of devolution. Regional Studies, 39(4), 405-420.

Rose, A. K. (2006). Size really doesn't matter: In search of a national scale effect. Journal of the Japanese and International Economies, 20(4), 482-507.

Rosemary, D., Bromley, F., and Rees, J.C.M. (1988). The first five years of the Swansea Enterprise Zone: an assessment of change, Regional Studies, 22(4), 263-275.

Schrank, A. (2001). Export processing zones: Free market islands or bridges to structural transformation? Development Policy Review, 19(2), 223-242.

Schwartz, H. (1994). Small states in big trouble: State reorganization in Australia, Denmark, New Zealand, and Sweden in the 1980s. World Politics, 46(4), 527-555. 
Turok, I. (1993). Inward investment and local linkages: how deeply embedded is 'Silicon Glen'? Regional Studies, 27(5), 401-417.

Vandemoortele, M., and Bird, K. (2011). Progress in economic conditions: Sustained success against the odds in Mauritius. London: Overseas Development Institute, http://www.developmentprogress.org/sites/developmentprogress.org/files/mauritius report master 0.pdf.

Wallis, J, J. (2006). The Concept of Systematic Corruption in American History. In Glaeser and Goldin (eds.), Corruption and Reform: Lessons from America's Economic History. Chicago: University of Chicago Press.

Wang, J. (2013). The economic impact of special economic zones: evidence from Chinese municipalities. Journal of Development Economics, 101(1), 133-147.

Weingast, B. R. (1995). The economic role of political institutions: Market-preserving federalism and economic development. Journal of Law, Economics, \& Organization, 11(1), 1-31.

Xu, C. (2011). The fundamental institutions of China's reforms and development. Journal of Economic Literature, 49(4), 1076-1151.

Xu, J., and Chung, C. K. L. (2014). 'Environment' as an evolving concept in China's urban planning system. International Development Planning Review, 36(4), 391-412. 
Yeung, Y. M., Lee, J., and Kee, G. (2009). China's special economic zones at 30. Eurasian Geography and Economics, 50(2), 222-240. 
'Quoted in 'Not so special,' the Economist, April 4, 2015.

ii Shenzhen is listed as having a population of 15 million in 2013.

iii See the online Appendix for a further exposition of the problems with the 'foreignness' argument.

iv Sensitivity analyses, not shown here, also attempted BMA using a multivariate Gaussian prior instead of the WALS approach. While there were marginal differences in $t$-stats, no variable had its decision on inclusion/exclusion changed as a result of the different priors.

${ }^{v}$ The fact that this cross-sectional data is averaged, essentially a long differencing over time, creates a capture of country-specific fixed-effects.

vi Given the relatively modest time-series for some of our data, the preferred approach for spatial dependence, the Driscoll-Kraay standard error framework, is not appropriate. 